\title{
Lithium Ordering in Next-Generation High-Voltage Lithium-Rich Layered Oxide Cathode Battery Materials
}

\author{
Michael Behr ${ }^{1}$, Michael Lowe ${ }^{1}$, Britt Vanchura ${ }^{1}, \mathrm{Fu}_{\text {Zhou }}{ }^{1}$, Wenjuan Liu ${ }^{1}$, Jia Liu ${ }^{1}$ \\ ${ }^{1}$ The Dow Chemical Company, Midland, MI, USA
}

Lithium-rich layered oxide cathode materials, with general formula $\mathrm{Li}_{1+\alpha} \mathrm{MO}_{2}(\mathrm{M}=$ transition metal or combination of metals), represent the next generation of high-voltage, high-capacity Li-ion battery cathode materials for plug-in electric vehicle applications. These materials offer up to 90\% increased lithium capacity, increased safety, and lower cost potential compared to incumbent $\mathrm{LiMO}_{2}$ positive electrode active materials such as $\mathrm{LiCoO}_{2}$ or $\mathrm{Li}\left[\mathrm{Ni}_{\mathrm{x}} \mathrm{Mn}_{\mathrm{y}} \mathrm{Co}_{1-\mathrm{x}-\mathrm{y}}\right] \mathrm{O}_{2}$.

In this study, transmission electron microscopy (TEM), electron diffraction (ED), x-ray energydispersive spectroscopy (XEDS) and x-ray diffraction (XRD) techniques were used to characterize these structurally-complex materials both in their pristine as-synthesized state, and after extensive electrochemical cycling. As synthesized, both ED and XRD reveal the overall monoclinic C2/m symmetry, indicating the presence of lithium ordering in transition-metal layers, similar to its parent $\mathrm{Li}_{2} \mathrm{MnO}_{3}$ crystal structure. However, it was found that this lithium ordering is not uniformly present throughout the sample. Convergent-beam electron diffraction (CBED) obtained from numerous nanometer-size regions across single nanoparticles reveal the presence of domains with trigonal R-3m symmetry, indicating disordered transition metal layers similar to the $\mathrm{LiCoO}_{2}$ structure. Additional high-resolution imaging confirms that ordered lithium-rich domains are inter-grown with Li-poor domains, over length scales $\sim 1-3 \mathrm{~nm}$, and randomly distributed throughout the sample. Upon electrochemical cycling, conversion from a layered crystal structure to spinel-like structure was captured as a function of number of cycles using both dark-field imaging and CBED.

Cathode nanoparticles were synthesized from Ni, Mo, and Co metal and lithium carbonate precursors. Precursor powders were mixed together using ball-milling processes, and then heat-treated at $850-$ $1050{ }^{\circ} \mathrm{C}$ for $\sim 10$ hours to convert to $\sim 100-200 \mathrm{~nm}$ particles $\mathrm{Li}_{1+\alpha}\left[\mathrm{Ni}_{\mathrm{x}} \mathrm{Mn}_{\mathrm{y}} \mathrm{Co}_{1-\mathrm{x}-\mathrm{y}}\right] \mathrm{O}_{2}$.

Figure 1 shows the inter-grown $\mathrm{C} 2 / \mathrm{m}$ and R-3m structures present within a single nanoparticle of assynthesized $\mathrm{Li}_{1+\alpha}\left[\mathrm{Ni}_{\mathrm{x}} \mathrm{Mn}_{\mathrm{y}} \mathrm{Co}_{1-\mathrm{x}-\mathrm{y}}\right] \mathrm{O}_{2}$. Nanometer size regions exhibiting either monoclinic or trigonal character were observed by CBED patterns collected from the nanocrystal. Specificially, CBED patterns were collected from regions spaced $\sim 10 \mathrm{~nm}$ apart along the indicated lines from a [001]oriented nanoparticle. The relative intensities of the unique $\mathrm{C} 2 / \mathrm{m}$ (blue) and $\mathrm{R}-3 \mathrm{~m}$ (black) diffraction spots were evaluated for each diffraction pattern, and their ratio $\left(\mathrm{I}_{\mathrm{C} 2 / \mathrm{m}} / \mathrm{I}_{\mathrm{R}-3 \mathrm{~m}}\right)$ is plotted as a function of probe position across the nanoparticle. As is evident from this plot, nanometer size regions of R-3m and $\mathrm{C} 2 / \mathrm{m}$ symmetry are present and distributed randomly throughout the nanocrystal. Blue arrows indicate regions with high $\mathrm{C} 2 / \mathrm{m}$ diffraction spot intensity, and thus indicate high levels of Li content and ordering. The variation in intensity ratio further indicates that lithium content and ordering varies continuously throughout the nanoparticle, consistent with a solid-solution of these two phases. This finding is consistent with previous findings that the stochastic distribution of $\mathrm{C} 2 / \mathrm{m}$ and $\mathrm{R}-3 \mathrm{~m}$ local structures is determine both by the $\mathrm{Li} / \mathrm{Me}$ ratio, and $(\mathrm{Ni}+\mathrm{Co}) / \mathrm{Mn}$ ratio $[1,2]$.

Figure 2 shows images and diffraction patterns of materials cycled for 2 and 200 cycles. Upon 
electrochemical cycling, diffraction patterns reveal the appearance of new diffraction spots, whose spacings and symmetries are consistent with that of Fd3m spinel. After two cycles, dark-field images show that nanoparticle surfaces exhibit spinel-like structure, yet the layered R-3m and C2/m structures remain throughout the bulk. However, after 200 cycles, only R-3m and spinel-like diffraction patterns are observed, indicating the loss of Li ordering, and migration of transition metal ions into the Li layers. In addition, new nm-size crystalline facets are observed, indicating migration and recrystallization.

\section{References}

[1] M. Gu et al, Nano Letters 12 (2012), p. 5186.

[2] J. Bareno et al, Chemistry of Materials 23 (2011), p. 2039.

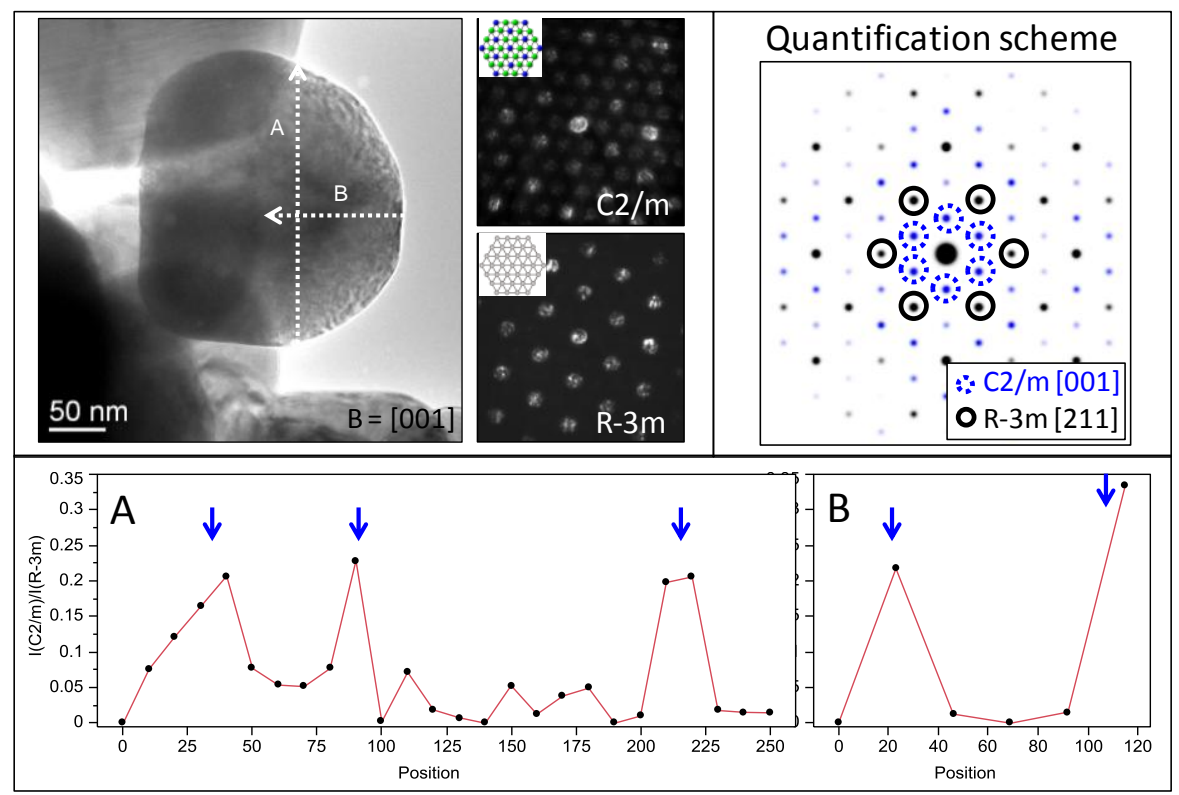

Figure 1. (upper left) Bright-field TEM image of a single cathode nanoparticles with representative $\mathrm{C} 2 / \mathrm{m}$ and $\mathrm{R}-3 \mathrm{~m}$ CBED patterns obtained along the indicated lines. (upper right) The quantification scheme used to evaluate the degree of $\mathrm{C} 2 / \mathrm{m}$ character from each $\mathrm{CBED}$ pattern. (bottom) Intensity ratio $\mathrm{I}_{\mathrm{C} 2 / \mathrm{m}} / \mathrm{I}_{\mathrm{R}-3 \mathrm{~m}}$ plotted as a function of
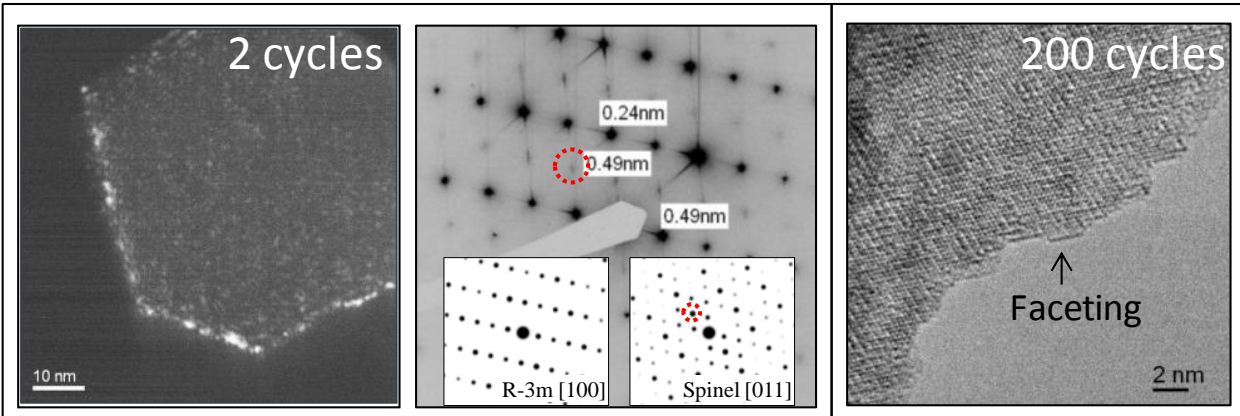

Figure 2. (Left) Dark-field image of nanoparticle after 2 cycles produced with weak spinel diffraction spot indicated (simulated spinel and R-3m pattern shown in inset) shows spinel phase distributed on the surface of the nanoparticles. (Right) HRTEM image of nanoparticles surface after 200 cycles shows formation of new facets. 